\title{
Balance Analysis and Improvement of Furniture Mixed Flow Production Line in Multi - Variety Small Batch Environment
}

\author{
Yanlin Zhao ${ }^{1, *}$ \\ ${ }^{1}$ Panzhihua University, Panzhihua city, Sichuan province, China \\ *Corresponding author
}

\begin{abstract}
As the user demand for furniture product diversification and personalized, the traditional single object assembly line production has become a serious impediment to the development of the enterprise, so the more varieties of small batch mixed flow under the environment of furniture production pattern has the necessity. The author with some furniture enterprise as the research object, on a single object assembly line production based on the analysis of the status quo, in the company $M$ D, E, $F$ class product mixed flow line balancing analysis and improvement, build production network diagram, using heuristic algorithm to calculate the reasonable mixed flow production line, the final mixed flow line than the original single line efficiency between $30.01-43.96 \%$, save labor costs 40700yuan/a directly. The results show that the mixed flow production line has a positive effect on enterprise cost, flexible production and market demand.
\end{abstract}

Keywords-production line balancing; production line improvement; furniture production; multi-product mixed production line

\section{INTRODUCTION}

The traditional high-volume furniture production pattern faces severe challenges, because it can't provide diversity and personalized furniture products to the user. In this context, with the development of manufacturing industry in the information age, rapid development of mass customization becomes mainstream mode. Mass customization furniture needs the support of flexible manufacturing system, and flexible manufacturing is a typical multiple species and small batch production. But now most of the factory design belongs to the furniture enterprisesuses products in enormous quantities and according to the characteristics of the product process to arrange the production model. This will greatly limit the production of personalized demand for furniture. Therefore, in this market environment of multiple species and small batch furniture production, we need to implement the mixed-model production line urgently to meet the demand of mass customization production mode.

Based on the above point of view, the author takes a furniture enterprise as the research object. On the basis of analyzing the present situation of the workshop, this paper uses heuristic algorithm to improve the production line of multiple species and small batch mixed flow. Finally, the author evaluated the optimization effect of mixed flow production line in order to provide reference and guidance to furniture enterprises, which want to construct a multiple-variety and small batch production line.

\section{NOW ANALYSIS}

\section{A. Workshop Analysis}

The company mainly engages in market research, design and production of cloth - sofa. On average, the company produces about 130 sets of sofas a day, and the styles and colors of the products are numerous, but the processing process of the sofa is not very different. The company has four different products D, E, F and G belonging to category M., and the four products are produced by four production lines. The paper analyzes the four products by using the p-q analysis method. From the analysis, we know that D, E and F products account for $65.04 \%$ percent of total production and $\mathrm{G}$ products account for $34.96 \%$ percent, and the four products are similar, but $G$ products belong to Special-shaped customization. This means that the customer ordered the product has more special requirements. Therefore, the product should be produced in little-variety production mode rather than on a mixed-model production line. Because the daily demand for $\mathrm{D}, \mathrm{E}$ and $\mathrm{F}$ products is lower than the daily production capacity of the production line, so these three products are produced in a multi-variety mixed-model production line. The author will carry on mixed flow production to $\mathrm{D}, \mathrm{E}$ and $\mathrm{F}$ products, then equilibrium analysis and improvement of the mixed-model production lines of $\mathrm{D}, \mathrm{E}$ and $\mathrm{F}$ products.

\section{B. Equilibrium Analysis of the Original Workshop Production Line}

Here are a total of four production lines 1\#, 2\#, 3\# and 4\# in the workshop, which belong to the little-variety production line. Because of the unreasonable distribution of the staff and the content of the workstation in each assembly line, the assembly line is often stagnant, the accumulation of products on the production line is serious, the load of each position is uneven, and the efficiency of the production line is low. Due to the limitation of the length of the article, the author takes the D product produced by the 1 \# line as an example, and the working hours of each workstation are shown in table 1. 
TABLE I. WORKING HOURS

\begin{tabular}{|c|c|c|c|c|}
\hline $\mathbf{N}$ & $\begin{array}{c}\text { Number of } \\
\text { People }\end{array}$ & Time & $\begin{array}{c}\text { Total } \\
\text { Time(min) }\end{array}$ & $\begin{array}{c}\text { Standard } \\
\text { Time(min) }\end{array}$ \\
\hline 1 & 1 & 3.18 & 3.18 & 3.5 \\
\hline \multirow{4}{*}{2} & \multirow{4}{*}{1} & 1.91 & \multirow{4}{*}{8.36} & \multirow{4}{*}{9.2} \\
\hline & & 2.45 & & \\
\hline & & 2.18 & & \\
\hline & & 1.82 & & \\
\hline \multirow{4}{*}{3} & \multirow{4}{*}{1} & 2.73 & \multirow{4}{*}{8.45} & \multirow{4}{*}{9.3} \\
\hline & & 2.27 & & \\
\hline & & 2.27 & & \\
\hline & & 1.18 & & \\
\hline \multirow{2}{*}{4} & \multirow{2}{*}{1} & 3.18 & \multirow{2}{*}{5} & \multirow{2}{*}{5.5} \\
\hline & & 1.82 & & \\
\hline \multirow{2}{*}{5} & \multirow{2}{*}{1} & 3.18 & \multirow{2}{*}{5} & \multirow{2}{*}{5.5} \\
\hline & & 1.82 & & \\
\hline \multirow{2}{*}{6} & \multirow{2}{*}{1} & 2.18 & \multirow{2}{*}{3.82} & \multirow{2}{*}{4.2} \\
\hline & & 1.64 & & \\
\hline 7 & 1 & 1.18 & 1.18 & 1.3 \\
\hline 8 & 1 & 1.73 & 1.73 & 1.9 \\
\hline 9 & 1 & 4.36 & 4.36 & 4.8 \\
\hline \multirow{2}{*}{10} & \multirow{2}{*}{1} & 0.82 & \multirow{2}{*}{1.91} & \multirow{2}{*}{2.1} \\
\hline & & 1.09 & & \\
\hline 11 & 1 & 1.82 & 1.82 & 2.0 \\
\hline 12 & 1 & 3.27 & 3.27 & 3.6 \\
\hline $\begin{array}{l}\text { Total } \\
\text { Time }\end{array}$ & 48.09 & $\begin{array}{l}\text { Bottleneck } \\
\text { Time }\end{array}$ & 8.45 & 52.9 \\
\hline
\end{tabular}

Note, the operating time in table 1 is the standard time, and the standard time $=$ the normal time $(1+$ time allowancerate), in which time allowance rate is $10 \%$.

The following table results can be obtained by balancing the production line.

TABLE II. D, E, F PRODUCTION LINE BALANCE ANALYSIS RESULT SUMMARY

\begin{tabular}{|c|c|c|c|c|c|}
\hline Name & $\begin{array}{c}\text { Bottleneck } \\
\text { Time }\end{array}$ & $\begin{array}{c}\text { Number } \\
\text { of People }\end{array}$ & $\begin{array}{c}\text { Total } \\
\text { Time }\end{array}$ & $\begin{array}{c}\text { balance } \\
\text { rate }\end{array}$ & $\begin{array}{c}\text { Efficiency } \\
\text { loss } \\
\text { (day/year) }\end{array}$ \\
\hline D & 9.3 & 12 & 52.9 & 47.4 & 192 \\
\hline E & 8.9 & 13 & 53.7 & 46.4 & 196 \\
\hline F & 10.5 & 13 & 61.4 & 44.98 & 201 \\
\hline
\end{tabular}

The original workshop has $1 \#, 2 \#, 3 \#$ and $4 \#$ production lines, which belong to the little-variety production line. The streamline balance ratio is below $50 \%$, which is equivalent that every line has waste of 192-201 days per year, causing great economic losses to the company.

\section{OPTIMIZATION AND IMPROVEMENT OF MULTI-VARIETY MIXED-MODEL PRODUCTION LINE}

\section{A. Preparation of Job Sequence Diagram}

To study the improvement of the balance of the mixedmodel production line, it is necessary to prepare a job sequence diagram of different products, and according to the characteristics of the mixed flow production line to preparea multivariate comprehensive job sequence diagram. On the mixed production flow line, although different products have the same working elements, their processing time is different. As a result, when drawing acomprehensive job sequence diagram, we can't simplyuse average to get the work time. The calculation formula for the job time of the integrated job element is shown below.
Symbol description.

1) $t_{j}$ represents the job time of comprehensive job sequence diagram.

2) $Q_{i}$ represents the proportion of product in total production.

3) represents the job time for the job element $j$ of product $i$.

$$
t_{j}=\sum_{i=1}^{n} Q_{i} t_{i j}
$$

We can draw the ratio of $\mathrm{D}, \mathrm{E}$ and $\mathrm{F}$ is $4,1,3$ from the average daily output of these three products. According to the working time and order of the $\mathrm{D}, \mathrm{E}$ and $\mathrm{F}$ products in table $1, \mathrm{D}$, $\mathrm{E}$ and $\mathrm{F}$ products are plotted in Comprehensive job sequence diagram.

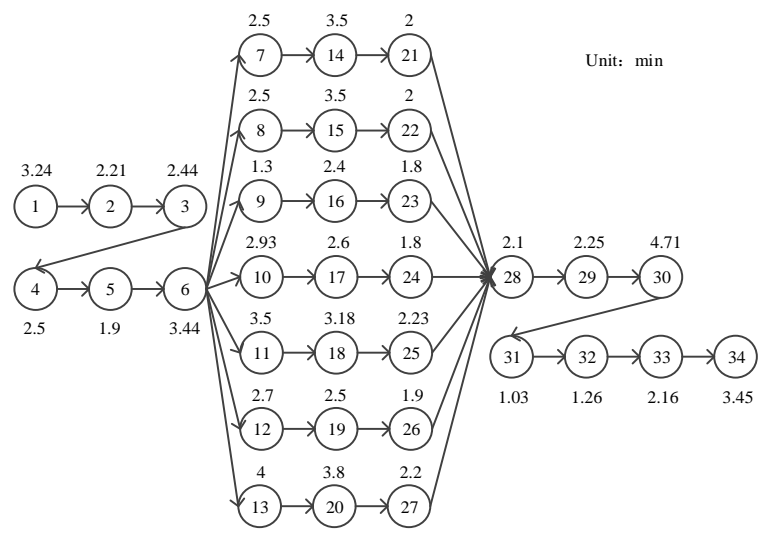

FIGURE I. COMPREHENSIVE JOB SEQUENCE DIAGRAM

\section{B. Solution of Heuristic Algorithm}

- Initial optimization.

Takt time is the time between the start of production of one unit and the start of production of the next unit. The determination of the takt time is to ensure that the production process follows a uniform beat. Therefore, the takt time is very important to realize the balance of production. The takt time is calculated at the effective working time of 8 hours per day, the average daily output of $\mathrm{D}, \mathrm{E}$ and $\mathrm{F}$ is 40,10 and 30.The minimum number of workstation isrefers to the production need at least the number of workstations, and it is the goal of the process synchronization.

The formula of calculating the minimum number of working places on the mixed flow line and takt time is shown below.

Symbol description,

1) $T_{x}$ represents an effective working time

2) ${ }^{N_{i}}$ represents the quantity of product $i$ in the plan period

3) $n$ represents the number of varieties

4) $t_{z i}$ represents the total operating time of the product $i$. 


$$
\begin{gathered}
r=T_{x} / \sum_{i=1}^{n} N_{i} \\
S_{\min }=\left[\frac{L}{T}\right]=\left[\left(\sum_{i=1}^{n} N_{i} t_{z i}\right) /\left(r \times \sum_{i=1}^{n} N_{i}\right)\right]
\end{gathered}
$$

The takt time of the mixed flow production line,

$$
r=(1 \times 8 \times 60) /(40+10+30)=6 \mathrm{~min}
$$

The minimum number of working places,

$$
S_{\min }=\frac{40 \times 52.9+10 \times 53.7+30 \times 61.4}{6 \times(40+10+30)}=[9.36]=10
$$

Due to space limitation, the calculation process of heuristic algorithm is not listed here. The calculation results are shown in the following table.

TABLE III. BALANCE RESULT OF MIXED FLOW PRODUCTION LINE

\begin{tabular}{|c|c|c|}
\hline $\mathbf{N}$ & Assigned Work -Ele & Time(min) \\
\hline 1 & 1、2、3 & 7.89 \\
\hline 2 & 4、5、6 & 7.84 \\
\hline 3 & 7、8、10 & 7.93 \\
\hline 4 & 9、11、13 & 8.8 \\
\hline 5 & 12、16、17 & 7.7 \\
\hline 6 & 14、18 & 6.68 \\
\hline 7 & 15、19、20 & 9.8 \\
\hline 8 & 21、22、25 & 6.23 \\
\hline 9 & 23、24、26、27 & 7.7 \\
\hline 10 & 28、29、30 & 9.06 \\
\hline 11 & 31、32、33、34 & 7.9 \\
\hline \multicolumn{2}{|c|}{ Total } & 87.53 \\
\hline
\end{tabular}

The balance rate of multivariate mixed flow production line is calculated as follows,

$$
\varepsilon=\frac{\sum t_{i}}{s \cdot r} \times 100 \%=\frac{87.53}{9.8 \times 11}=81.2 \%
$$

The paper can draw a conclusion from the balance rate of the mixed flow line. The mixed flow production of D, E and F products is realized by heuristic balance. And get the number of work stations and work time. However, this balance only considers the order of work elements and the working time of each position is close to the production meter, without taking into account the workload of the various job elements during the planning period. Because the furniture company implements a single shift production, and the effective working hours are 8 hours per day. Therefore, the total amount of work undertaken by each workstation should be less than or equal to 480 minutes, and the number of work stations that we get is not the minimum number of work stations.

Take the workstation 1 in table 3 as an example, and the total amount of work that the workstation should undertake during the planning period is calculated as follows, total workload undertaken by workstation $1=631>480$. Therefore, it does not meet the requirements of the mixed flow production line.

Therefore, there are still problems in multi-variety mixed flow production line, which needs further optimization. Because the position of the job element can also be adjusted according to the company's actual situation, the production line can be change to assembly line balancing to make the total work of each station less than 480 minutes.

- $\quad$ Further optimization

1) Calculate the amount of work undertaken by each job element during the planning period.

Because assembly line balancing requires a balance of production capacity, it is necessary to calculate the workload.

a) $\delta_{i}$ is the variety selection code, which is 1 when the variety has this job element, and 0 when the working element is not available.

b) ${ }^{t}$ represents the working time of job element $j$.

c) $\tau_{j}^{\prime}$ represents the amount of work should be completed within the planning period of a certain work element $j$ of the $i$ variety.

d) ${ }^{\tau}{ }_{j}$ represents the total amount of work undertaken by the job element $j$ of the whole variety on the mixed flow line

e) $k$ represents the number of job elements

f) $L$ represents the total amount of work undertaken by the job element of the whole variety on the mixed flow line

The calculation formula of the amount of work should be done during the planning period for a job element $j$ of the $i$ variety is as follows.

$$
\tau_{j}^{\prime}=N_{i} \cdot \delta_{i} \cdot t_{z j}
$$

The formula for calculating the total amount of work required to complete all product output on the mixed flow line is as follows.

$$
\tau_{j}=\sum_{i=1}^{n} \tau_{j}^{\prime}=\sum_{i=1}^{n} N_{i} \cdot \delta_{i} \cdot t_{z j}
$$

In excel, calculate the amount of work that each job element will undertake during the planning period, and the result of the calculation is shown following table. 
TABLE IV. THE AMOUNT OF WORK UNDERTAKEN BY EACH OPERATION ELEMENT WITHIN THE PLANNING PERIOD (UNIT, MIN)

\begin{tabular}{|c|c|c|c|c|c|c|c|c|}
\hline $\begin{array}{c}\text { Work- } \\
\text { Ele }\end{array}$ & $t_{z j}$ & $\delta_{D}$ & $\delta_{E}$ & $\delta_{F}$ & $\tau_{D}{ }^{\prime}$ & $\tau_{E}{ }^{\prime}$ & $\tau_{F}{ }^{\prime}$ & $\tau_{j}$ \\
\hline 1 & 3.24 & 1 & 1 & 1 & 129.50 & 32.38 & 97.13 & 259.0 \\
\hline 2 & 2.21 & 1 & 1 & 1 & 88.50 & 22.13 & 66.38 & 177.0 \\
\hline 3 & 2.44 & 1 & 1 & 1 & 97.50 & 24.38 & 73.13 & 195.0 \\
\hline 4 & 2.50 & 1 & 1 & 1 & 100.00 & 25.00 & 75.00 & 200.0 \\
\hline 5 & 1.90 & 1 & 1 & 1 & 76.00 & 19.00 & 57.00 & 152.0 \\
\hline$\ldots$ & $\ldots$ & $\ldots$ & $\ldots$ & $\ldots$ & $\ldots$ & $\ldots$ & $\ldots$ & $\ldots$ \\
\hline 34 & 3.45 & 1 & 1 & 1 & 138.00 & 34.50 & 103.50 & 276.0 \\
\hline Total & 87.53 & & & & 2167.3 & 560.23 & 1767.68 & 4495.2 \\
\hline
\end{tabular}

Because of the space limitation, only for example partial content.

2) Assembly line balancing

Job sequence diagramare divided into sixteen operational areas according to the order of operation. The first district, 1; the second district; the third district, 3; the fourth district,4; the fifth district, 5; the sixth district, 6; the seventh district, $7,8,9,10,11,12,13$; the eighth district, $14,15,16,17,18,19,20$; the ninth district, 21,22,23,24,25,26,27; the tenth district, 28; the eleventh district, 29; the twelfth district, 30; the thirteenth district, 31; the fourteenth district, 32; the fifteenth district, 33; the sixteenth district,34.

It is calculated on one working day equal to single shift system $(t \leq 480 \mathrm{~min})$. And keep the number of places of work as low as possible $\left(S_{\min }=10\right)$. In the same interval, the highest possible allocation of large values belongs to $\tau_{j}$. If the assignment cannot continue within an interval, the job element is moved to adjust.

The results of the process adjustment are shown in following table.

TABLE V. RESULT OF PROCESS SYNCHRONIZATION

\begin{tabular}{|c|c|c|c|c|c|c|}
\hline Interval & $\begin{array}{l}\text { Work } \\
\text {-Ele }\end{array}$ & $\tau_{j}$ & $\sum \tau_{j}$ & $\begin{array}{c}\text { Moving } \\
\text { Work - } \\
\text { Ele }\end{array}$ & $\begin{array}{c}\text { Cumulative } \\
\text { time after } \\
\text { interval } \\
\text { correction }\end{array}$ & WK \\
\hline I & 1 & 259.0 & 259 & & & \multirow{2}{*}{1} \\
\hline I & 3 & 195 & 454 & & & \\
\hline II & 2 & 177.0 & & $\begin{array}{c}\text { Moving } \\
\text { VII }\end{array}$ & & \\
\hline III & 3 & 195.0 & & $\begin{array}{c}\text { Moving } \\
\text { I }\end{array}$ & & \\
\hline IV & 4 & 200.0 & & $\begin{array}{c}\text { Moving } \\
\text { VI }\end{array}$ & & \\
\hline V & 5 & 152.0 & & $\begin{array}{l}\text { Moving } \\
\text { VII }\end{array}$ & & \\
\hline VI & 4 & 200.0 & 200 & & & \multirow{2}{*}{2} \\
\hline VI & 6 & 275.0 & 475 & & & \\
\hline VII & 2 & 177 & 177 & & & \multirow{3}{*}{3} \\
\hline VII & 5 & 152 & 329 & & & \\
\hline VII & 13 & 120 & 449 & & & \\
\hline VII & 7 & 100.0 & 100 & & & \multirow{7}{*}{4} \\
\hline VII & 8 & 100 & & $\begin{array}{c}\text { Moving } \\
\text { VIII }\end{array}$ & 100 & \\
\hline VII & 9 & 52.0 & 152 & & & \\
\hline VII & 10 & 117.2 & & $\begin{array}{l}\text { Moving } \\
\text { VIII }\end{array}$ & 152 & \\
\hline VII & 11 & 140 & 292 & & & \\
\hline VII & 12 & 27.0 & 319 & & & \\
\hline VII & 20 & 114 & 433 & & & \\
\hline
\end{tabular}

\begin{tabular}{|c|c|c|c|c|c|c|}
\hline Interval & $\begin{array}{l}\text { Work } \\
\text {-Ele }\end{array}$ & $\tau_{j}$ & $\sum \tau_{j}$ & $\begin{array}{c}\text { Moving } \\
\text { Work - } \\
\text { Ele }\end{array}$ & $\begin{array}{c}\text { Cumulative } \\
\text { time after } \\
\text { interval } \\
\text { correction }\end{array}$ & WK \\
\hline VIII & 8 & 100 & 100 & & & \multirow{4}{*}{5} \\
\hline VIII & 10 & 117.2 & 217.2 & & & \\
\hline VIII & 16 & 96.0 & 313.2 & & & \\
\hline VIII & 18 & 127.2 & 440.4 & & & \\
\hline VIII & 20 & 114.0 & & $\begin{array}{c}\text { Moving } \\
\text { VII }\end{array}$ & & \\
\hline VIII & 14 & 140.0 & 140 & & & \multirow{4}{*}{6} \\
\hline VIII & 15 & 140.0 & 280 & & & \\
\hline VIII & 17 & 104.0 & 384 & & & \\
\hline VIII & 19 & 25.0 & 409 & & & \\
\hline IX & 21 & 80.0 & 80 & & & \multirow{7}{*}{7} \\
\hline IX & 22 & 80.0 & 160 & & & \\
\hline IX & 23 & 72.0 & 232 & & & \\
\hline IX & 24 & 72.0 & 304 & & & \\
\hline IX & 25 & 89.2 & 393.2 & & & \\
\hline IX & 26 & 19.0 & 412.2 & & & \\
\hline IX & 27 & 66.0 & 478.2 & & & \\
\hline$X$ & 28 & 168.0 & 168 & & & \multirow{3}{*}{8} \\
\hline XI & 29 & 180.0 & 348 & & & \\
\hline XII & 31 & 82.0 & 430 & & & \\
\hline XIII & 30 & 377.0 & 377 & & & \multirow{2}{*}{9} \\
\hline XIV & 32 & 100.8 & 477.8 & & & \\
\hline $\mathrm{XV}$ & 33 & 172.8 & 172.8 & & & \multirow{2}{*}{10} \\
\hline XVI & 34 & 276.0 & 448.8 & & & \\
\hline
\end{tabular}

Evaluate the results of assembly line balancing,

Symbol description,

a) $S$ represents minimum number of work stations

b) $r$ represents the takt time

c) $t_{z i}$ represents the total time required to complete a unit product

The calculation formula of working time loss (B) of mixed flow production line is as follows.

$$
B=s \cdot r \cdot \sum_{i=1}^{n} N_{i}-\sum_{i=1}^{n} N_{i} \cdot t_{\mathrm{zi}}
$$

The working time loss,

$$
B=10 \times 6 \times(40+10+30)-(40 \times 52.9+10 \times 53.7+30 \times 61.4)=305
$$

The formula for calculating the working time loss rate (D) of mixed flow production line is as follows.

$$
D=B / s \cdot r \cdot \sum_{i=1}^{n} N_{i}
$$

The working time loss rate:

$$
D=\frac{305}{10 \times 6 \times(40+10+30)} \times 100 \%=6.35 \%
$$

The formula for calculating the equipment load rate of mixed flow production line is as follows. 


$$
\eta=\sum_{i=1}^{n} N_{i} t_{z i} / s \cdot r \cdot \sum_{i=1}^{n} N_{i}
$$

The equipment load rate:

$$
\eta=\frac{4495.2}{4800} \times 100 \%=93.65 \%
$$

The analysis shows that the results of the assembly line balancing in table 5 are ideal, and meet the requirements of mixed flow production

3) Determine standard operating time

The standard operating time calculation results of each work station are shown in following table.

TABLE VI. D, E AND F STANDARD OPERATING TIME OF EACH

\begin{tabular}{|c|c|c|c|c|c|c|c|c|}
\hline \multirow[b]{2}{*}{ WK } & \multirow{2}{*}{$\begin{array}{l}\text { Work } \\
\text {-Ele }\end{array}$} & \multirow[b]{2}{*}{$t_{z}(\min )$} & \multicolumn{2}{|r|}{ D } & \multicolumn{2}{|r|}{$\mathbf{E}$} & \multicolumn{2}{|r|}{$\mathbf{F}$} \\
\hline & & & $\delta_{D}$ & process & $\delta_{E}$ & process & $\delta_{F}$ & process \\
\hline \multirow{2}{*}{1} & 1 & 3.24 & 1 & \multirow{2}{*}{5.68} & 1 & \multirow{2}{*}{5.68} & 1 & \multirow{2}{*}{5.68} \\
\hline & 3 & 2.44 & 1 & & 1 & & 1 & \\
\hline \multirow{2}{*}{2} & 4 & 2.5 & 1 & \multirow{2}{*}{5.94} & 1 & \multirow{2}{*}{5.94} & 1 & \multirow{2}{*}{5.94} \\
\hline & 6 & 3.44 & 1 & & 1 & & 1 & \\
\hline \multirow{3}{*}{3} & 2 & 2.21 & 1 & \multirow{3}{*}{4.11} & 1 & \multirow{3}{*}{4.11} & 1 & \multirow{3}{*}{8.11} \\
\hline & 5 & 1.9 & 1 & & 1 & & 1 & \\
\hline & 13 & 4 & & & & & 1 & \\
\hline \multirow{5}{*}{4} & 7 & 2.5 & 1 & \multirow{5}{*}{3.8} & & \multirow{5}{*}{6.2} & & \multirow{5}{*}{7.3} \\
\hline & 9 & 1.3 & 1 & & & & & \\
\hline & 11 & 3.5 & & & 1 & & 1 & \\
\hline & 12 & 2.7 & & & 1 & & & \\
\hline & 20 & 3.8 & & & & & 1 & \\
\hline \multirow{4}{*}{5} & 8 & 2.5 & 1 & \multirow{4}{*}{4.9} & & \multirow{4}{*}{6.11} & & \multirow{4}{*}{6.11} \\
\hline & 10 & 2.93 & & & 1 & & 1 & \\
\hline & 16 & 2.4 & 1 & & & & & \\
\hline & 18 & 3.18 & & & 1 & & 1 & \\
\hline & 14 & 3.5 & 1 & & & & & \\
\hline 6 & 15 & 3.5 & 1 & 7 & & 51 & & 26 \\
\hline 0 & 17 & 2.6 & & 1 & 1 & 0.1 & 1 & 2.0 \\
\hline & 19 & 2.5 & & & 1 & & & \\
\hline & 21 & 2.00 & 1 & & & & & \\
\hline & 22 & 2.00 & 1 & & & & & \\
\hline & 23 & 1.80 & 1 & & & & & \\
\hline 7 & 24 & 1.80 & & 5.8 & 1 & 5.93 & 1 & 6.23 \\
\hline & 25 & 2.23 & & & 1 & & 1 & \\
\hline & 26 & 1.90 & & & 1 & & & \\
\hline & 27 & 2.20 & & & & & 1 & \\
\hline & 28 & 2.10 & 1 & & 1 & & 1 & \\
\hline 8 & 29 & 2.25 & 1 & 5.38 & 1 & 5.38 & 1 & 5.38 \\
\hline & 31 & 1.03 & 1 & & 1 & & 1 & \\
\hline 9 & 30 & 4.71 & 1 & 597 & 1 & 597 & 1 & 507 \\
\hline 9 & 32 & 1.26 & 1 & 3.91 & 1 & 3.91 & 1 & 0.91 \\
\hline 10 & 33 & 2.16 & 1 & 561 & 1 & 561 & 1 & 561 \\
\hline 10 & 34 & 3.45 & 1 & 5.61 & 1 & 5.61 & 1 & 5.61 \\
\hline & & 87.53 & & 54.19 & & 56.03 & & 58.93 \\
\hline
\end{tabular}
PROCEDURE

C. Evaluation of Balanced and Optimized Effect of Multivariety Mixed Flow Production Line

By calculating the amount of work to be carried out by each of the elements during the planning period, synchronization the production process and determining the standard operating time of $\mathrm{D}, \mathrm{E}$ and $\mathrm{F}$ products in each process. The balance rate of multi-variety mixed flow production line after optimization is calculated as follows.

$$
\varepsilon=\frac{\sum t_{i}}{S \cdot r} \times 100 \%=\frac{87.53}{10 \times 13.93} \times 100 \%=62.84 \%
$$

It is not obvious to improve the balance rate of mixed flow production line after optimization. Because the work element assigned to each position on the mixed flow line is not the work element involved in all the products participating in the mixed flow, the balance rate of the mixed flow line is not representative. Therefore, the balance rate of each product after participating in the mixed flow should be calculated separately.

The balance rate of $\mathrm{D}, \mathrm{E}$ and $\mathrm{F}$ products is calculated as follows.

$$
\begin{aligned}
& \varepsilon_{D}=\frac{\sum t_{i}}{S \cdot r} \times 100 \%=\frac{54.19}{10 \times 7} \times 100 \%=77.41 \% \\
& \varepsilon_{E}=\frac{\sum t_{i}}{S \cdot r} \times 100 \%=\frac{56.03}{10 \times 6.2} \times 100 \%=90.37 \% \\
& \varepsilon_{F}=\frac{\sum t_{i}}{S \cdot r} \times 100 \%=\frac{58.93}{10 \times 8.11} \times 100 \%=72.66 \%
\end{aligned}
$$

D products balance rate increased by $30.01 \%$, E products balance rate increased by $43.96 \%$ and $\mathrm{F}$ products balance rate increased by $27.68 \%$. The average annual income of the workers in the furniture company is 40,000yuan /a. The per capita labor cost of product $\mathrm{D}, \mathrm{E}$ and $\mathrm{F}$ is shown below.

D products, Saving per capita labor costs $=4 * 30.01 \%=12000$ yuan $/ \mathrm{a}$

E products, Saving per capita labor costs $=4 * 43.96 \%=17600$ yuan $/ \mathrm{a}$

F products, Saving per capita labor costs $=4 * 27.68 \%=11100 \mathrm{yuan} / \mathrm{a}$

\section{SUMMARY}

At present, most of the production line design of furniture enterprises adopts the production mode of mass single object assembly line. This will greatly limit the personalized demand for furniture production. Therefore, in order to solve the production mode of multi-variety small batch environment, this paper focuses on a furniture enterprise to analyze and improve the balance of the mixed flow production line of $\mathrm{M}$ products $\mathrm{D}$, $\mathrm{E}$ and $\mathrm{F}$ in a furniture enterprise. By analyzing the present situation of the workshop, constructing the production network diagram and using heuristic algorithm to solve the reasonable mixed flow production line. Finally, the mixed flow line increased to between 30.01 and 43.96 from the original single assembly line. Saving labor cost, 407,000yuan/a directly. The 
results show that the mixed production line plays a positive role in enterprise cost, flexible production and market demand.

\section{REFERENCES}

[1] Xiong Xianqing, Wu Zhuihui. The development status and application technology of mass customization furniture [J]. Journal of nanjing forestry universit,2013, 37(4),156-162.

[2] Xiong Xianqing, Wei Yaling, Fang Luwu. Research on rapid response mechanism and key technology of mass customization furniture [J]. Forest industry, 2016, 43(1),47-52.

[3] Yang Ting, Zhang Dinghua, Chen Bing. The method of production capacity planning for mixed flow production line based on weighted network.[J]. Chinese mechanical engineering, 2011, 22(7),824,829.

[4] Miao Xin, Wang Futian. The construction algorithm of manufacturing production line model $[\mathrm{J}]$. Journal of changchun university), 2006, 27(2),131-134. 